\title{
BMJ Open Job type and other socio-demographic factors associated with participation in a national, cross-sectional study of Danish employees
}

\author{
Nina Føns Johnsen, ${ }^{1}$ Birthe Lykke Thomsen, ${ }^{1}$ Jørgen Vinsløv Hansen, ${ }^{1}$ \\ Birgitte Schütt Christensen, ${ }^{1}$ Reiner Rugulies, ${ }^{1,2,3}$ Vivi Schlünssen ${ }^{1,4}$
}

To cite: Johnsen NF, Thomsen BL, Hansen JV, et al. Job type and other sociodemographic factors associated with participation in a national, cross-sectional study of Danish employees. BMJ Open 2019;9:e027056. doi:10.1136/ bmjopen-2018-027056

- Pre-publication history and additional material is published online only. To view please visit the journal online (http://dx.doi. org/10.1136/bmjopen-2018027056).

Received 3 October 2018 Revised 27 May 2019

Accepted 7 June 2019

Check for updates

(C) Author(s) (or their employer(s)) 2019. Re-use permitted under CC BY-NC. No commercial re-use. See rights and permissions. Published by BMJ.

${ }^{1}$ Department of Epidemiology and Surveillance, National

Research Centre for the Working

Environment, Copenhagen,

Denmark

${ }^{2}$ Department of Public Health, University of Copenhagen,

Copenhagen, Denmark

${ }^{3}$ Department of Psychology, University of Copenhagen,

Copenhagen, Denmark

${ }^{4}$ Department of Public Health,

Danish Ramazzini Centre,

Aarhus University, Aarhus,

Denmark

Correspondence to

Mrs. Nina Føns Johnsen;

njohnsen@hjerteforeningen.dk

\section{ABSTRACT}

Objectives Participation in population-based surveys and epidemiological studies has been declining over the years in many countries. The aim of this study was to examine the association between job type and participation in the work environment and health in Denmark survey with/ without taking into account other socio-demographic factors.

Design Cross-sectional survey using questionnaire data on working environment and registry data on job type, industry and socio-economic variables.

Setting The work environment and health study. Participants A total of 50806 employees (15767 in a stratified workplace sample; 35039 in a random sample) working at least 35 hours/month and earning at least 3000 Danish Krones.

Outcome measures The outcome was participation (yes/ no) and logistic regression was used to estimate the OR for participation with $95 \% \mathrm{Cl}$.

Results In the random sample, women were more likely to participate than men, and married/non-married couples were more likely to participate than persons living alone or more families living together. Participation increased with higher age, higher annual personal income, higher education and Danish origin, and there were marked differences in participation between job types and geographical regions. For armed forces, craft and related trade workers, and skilled agricultural, forestry and fishery workers, the association between job type and participation was strongly attenuated after adjustment for sex and age. Additional adjustment for annual income, education, cohabitation, country of origin and geographical region generally attenuated the association between job type and participation. Similar results were found in the stratified workplace sample.

Conclusion In this population of Danish employees, participation varied across types of jobs. Some but not all the variation between job types was explained by other socio-demographic factors. Future studies using questionnaires may consider targeting efforts to (sub-) populations, defined by job type and other factors, where response probability is particularly important.

\section{INTRODUCTION}

Decreasing participation has been observed in population-based surveys and
Strengths and limitations of this study

- The large sample size is considered a major strength.

- The national coverage means that employees in all geographical areas and job groups are included.

- The access to almost complete registry data for both participants and non-participants limits potential information bias.

- However, the relatively crude job groups may potentially be too crude to identify an association between participation and job type.

- The missing information on education for 1400 individuals could have changed the association under study, but the sensitivity analyses did not confirm this.

epidemiological studies over years in many countries. ${ }^{1-3}$ This potentially hampers the possibility of achieving unbiased results as non-participation can not only influence prevalence estimates of environmental and occupational exposures but may also introduce selection bias in exposure-outcome associations ${ }^{24-7}$ if non-participation is related to both exposure and outcome. The generalisability of the results of an analysis is not an inherent property of the study population but depends on the target population as well as the combination of exposure, outcome and additional covariates considered in the analysis in question. Pearl and Bareinboim ${ }^{89}$ provide a formalisation of the necessary and sufficient conditions required for generalisability of causal effects together with a structured, graphical approach to identify the relevant scientific assumptions.

The aim of the national questionnaire survey 'Work Environment and Health in Denmark' (WEHD) is to monitor the work environment and health among employees in Denmark. The data are used for governmental monitoring purposes and evidence, 
informing the working environment inspections, developing working environment initiatives, as a reference for job satisfaction surveys, and also for exposure-outcome research. The 2012 survey was the first of five planned surveys until 2020, including questions about physical and psychosocial working environment, health-related behaviours, working ability and health among a large group of employees.

Participation in surveys varies according to age and $\operatorname{sex}^{6} 7^{10-12}$ and occupational social class. ${ }^{13}$ Individuals with a low income or low educational level are typically under-represented in epidemiological studies and population-based surveys in Western countries. ${ }^{6} 710-17$

One of the main aims of the WEHD is to generate work environment profiles for different job types (as defined by the DISCO-08 classification system, which is a Danish, and slightly modified version of International Standard Classification of Occupations 2008 (ISCO08)). Job type is an important indicator of socioeconomic status together with education and income, and it is possible that job type may capture some or all of the effect of income and education. Furthermore, job type may have an influence per se for example, if the job type reflects the individual's practical or social/cultural possibilities of responding. To our knowledge, job type has not been studied in relation to participation in observational studies. Because Danish national registers are available for research purposes, we had a unique opportunity to conduct a study with the aim of examining the associations between job types and other socio-demographic factors and participation in WEHD 2012. We hypothesised that job type is a strong independent determinant for participation, and that job type may capture (some or all of) the variation in education and/ or income. The WEHD study is used for estimation of both prevalence and exposure-outcome associations and for both estimations response representativity is crucial.

\section{METHODS \\ Study population}

The study was conducted as a cross-sectional survey. Figure 1 shows the flow chart for the WEHD 2012 populations. The source population for WEHD 2012 was all individuals living in Denmark, aged 18-64years, who were employed between 30 November 2011 and 31 January 2012 , worked $\geq 35$ hours / month and earned at least 3000 Danish Krones $(\mathrm{Kr})$ per month ( US\$460).

Two samples fulfilling these criteria were drawn by Statistics Denmark. The first sample of employees (the stratified workplace sample) was drawn from 1060 selected workplaces (with at least 10 full-time equivalent employees). These companies were sampled stratified according to industry (five categories) and workplace size (small workplaces with 10-99 full-time equivalent employees; medium-sized workplaces with 100-499 fulltime equivalent employees; large workplaces with at least 500 full-time equivalent employees). This target population consisted of 198789 individuals, of whom $29027 \mathrm{had}$

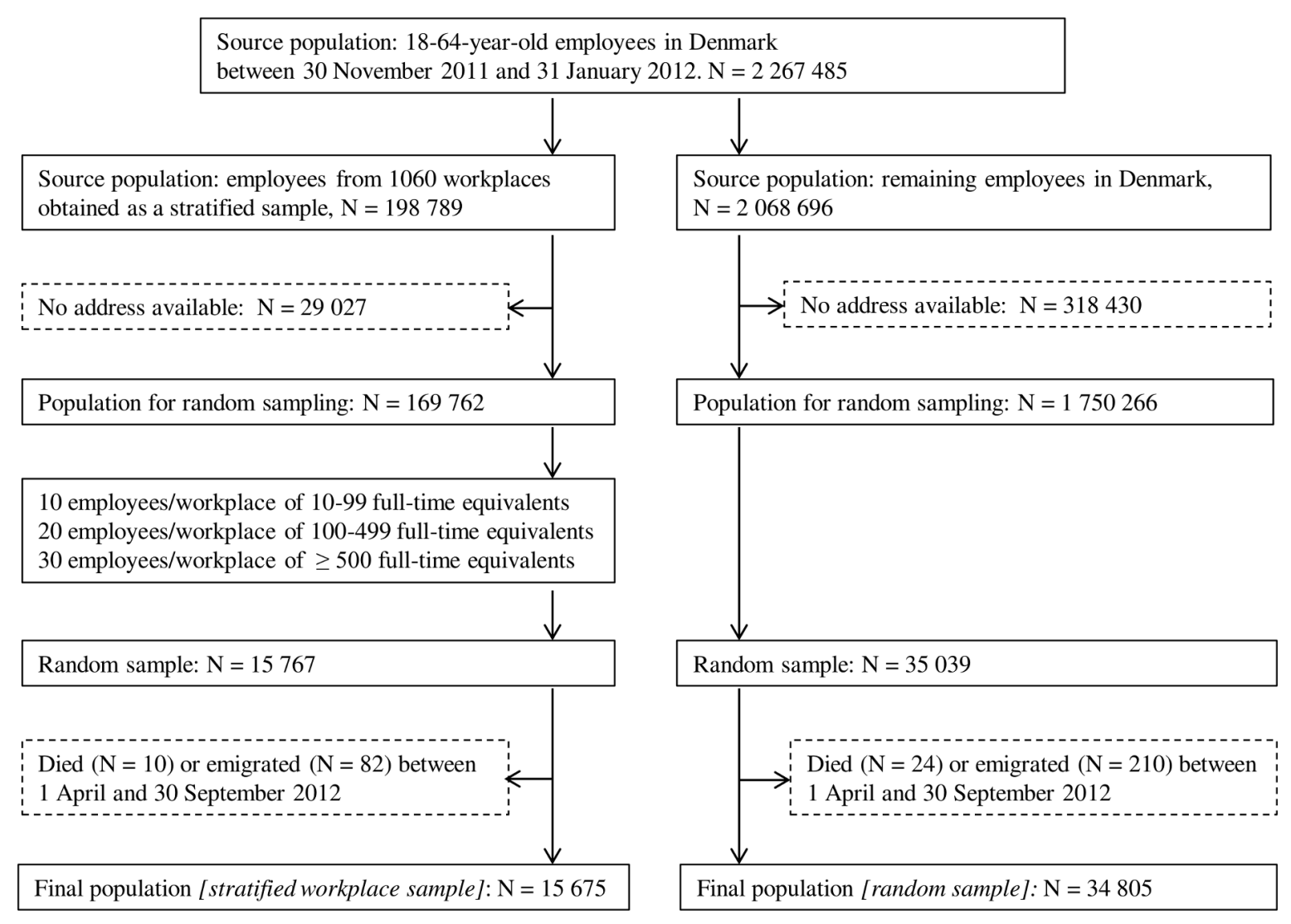

Figure 1 Flow chart for Work, Environment and Health 2012. 
a secret address or a so-called 'research protection' in the Civil registration number (CPR) registry (a protection of own information, that any individual in Denmark could request before 2014 and that implied that researchers were prevented from getting the contact information needed to invite potential participants), leaving 169762 individuals for the final population. A total of 10 employees were selected randomly from each of the small workplaces (10-99 full-time equivalent employees), 20 employees were selected randomly from the medium-sized workplaces (100-499 full-time equivalent employees) and 30 employees were selected randomly from the large workplaces (at least 500 full-time equivalent employees) resulting in 15767 eligible individuals. Of those, 10 died and 82 emigrated between 1 April and 30 September 2012, resulting in a final sample of 15675 employees.

The second sample (the random sample) was drawn from the population of 2068696 employees living in Denmark and not employed at the 1060 workplaces in the first sample. Of these, 318430 had a secret or 'research protected' address, leaving 1750266 individuals for the final target population. A random sample of 35039 employees was drawn from this population of which 24 died and 210 emigrated between 1 April and 30 September 2012, resulting in a final sample of 34805 employees. To ensure generalisability, the primary results of the article are based on the random sample of employees, and results from the analyses on the stratified workplace sample are included as online supplementary material.

\section{Data sources}

In April 2012 potential participants were invited by a postal letter, including a link to a web-based questionnaire. Non-responders of the first contact received a second postal letter with a link to the questionnaire and an enclosed paper questionnaire. After these two contacts, non-responders were contacted up to two times by phone by a commercial research institute. They were asked whether they were still working and offered a new paper questionnaire.

Participation was defined as answering at least one question in the questionnaire, regardless if the questionnaire was the online version, the paper version or answered by phone.

\section{Questionnaire data}

The questionnaire comprised 51 questions on physical and psychosocial working environment, health-related behaviours, working ability and health. The questions related to current employment (eg, length of employment, transportation, working hours, job security), psychosocial working environment, work accidents and safety, noise, vibrations, skin exposures, physical demands including lifting, self-rated work ability, seniority and pension, sleep, vitality, pain, chronic disease including mental disorders, smoking, alcohol use, height and weight.

\section{Registry data}

Information about country of origin, cohabitation, education, annual personal income and type of job was extracted from Statistics Denmark using the unique, Danish civil identification number ${ }^{18}$ given to every Danish citizen. The registers contain historic information that is collected continuously for the entire Danish population from the civil registration system, taxation authorities and all Danish worksites for whom it is compulsory to report certain information about their employees. ${ }^{19}$ Age was defined as age on 15 March 2012. Information on job type was collected from the Danish E-income Registry and was based on the first digit of the DISCO-08 classification code, the Danish, and slightly modified version of International Standard Classification of Occupations 2008 (ISCO08). ${ }^{20}$

\section{Definition of variables}

The outcome (participation) was defined as having answered at least one question in the questionnaire.

Job type was defined as one-digit ISCO08 number; sex had two levels (men and women); age was categorised in five categories $(18-24,25-34,35-44,45-54$ and 55-64years); annual personal income was categorised in three categories $(<250000 \mathrm{Kr} ; 250000-430000$ $\mathrm{Kr} ;>430000 \mathrm{Kr}$ ); education in six categories (compulsory school system, upper secondary education and university preparatory schools and vocational education, academic level, missing data on education (Danish origin), missing data (Western origin), missing data (non-Western origin)); cohabitation was categorised in three categories (married or unmarried couple, living alone, more families living together); country of origin was categorised in three categories (Denmark; Western country, not Denmark; Non-Western country); and regarding geographical region of residence, the five Danish regions were used (Copenhagen, Zealand, Northern Jutland, Middle Jutland, Southern Jutland).

\section{Statistical analyses}

In the initial descriptive analyses, frequencies of characteristics of participants and non-participants were presented for both the random sample and the stratified workplace sample. The following results are based only on the random sample (to ensure generalisability as mentioned in Methods).

Logistic regression models were used to estimate the OR with $95 \%$ CI for participation. OR for each independent factor was estimated in four models: (1) model 1unadjusted, (2) model 2-adjusted for age by sex, (3) model 3-model 2 further adjusted for personal income, education, cohabitation, country of origin and geographical region of residence and (4) model 4-model 3 further adjusted for job type. The full combination of age by sex (age in 1-year categories) was included in the analyses. The association of participation with income was modelled as a linear spline on the log-odds scale with knots in the quartiles: 262000; 337000; $427000 \mathrm{Kr}$. 
Table 1 Characteristics of participants and non-participants in the Work, Environment and Health 2012

\section{Random sample}

Participation, proportion (\%) Participants, N

\section{Stratified workplace sample}

Non- Participation, Non-

participants, $\mathbf{N}$ proportion (\%) Participants, $\mathbf{N}$ participants, $\mathbf{N}$

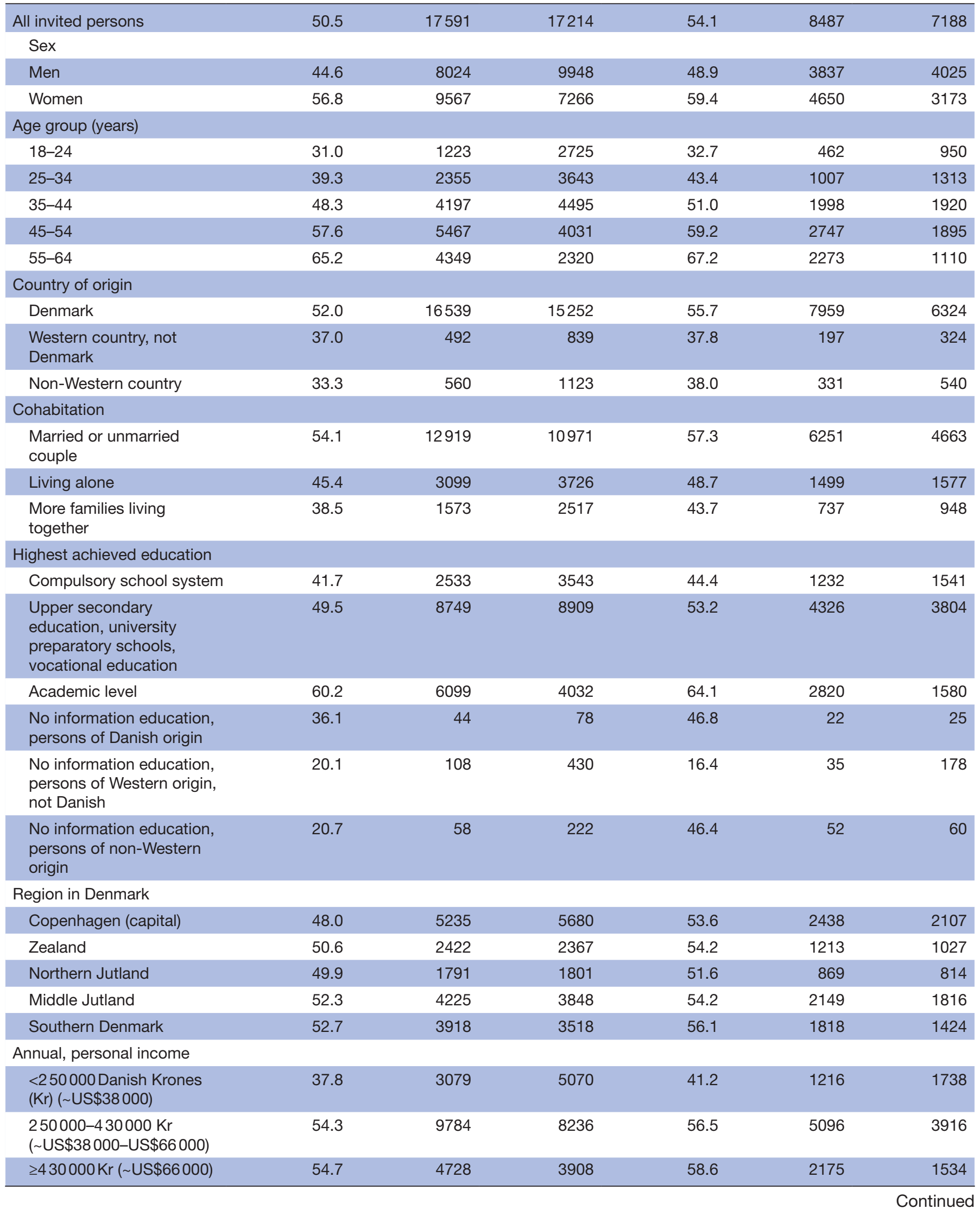




\begin{tabular}{|c|c|c|c|}
\hline Random sample & & Stratified workplace sample & \\
\hline $\begin{array}{l}\text { Participation, } \\
\text { proportion (\%) }\end{array}$ & $\begin{array}{l}\text { Non- } \\
\text { participants, } \mathbf{N}\end{array}$ & $\begin{array}{l}\text { Participation, } \\
\text { proportion (\%) Participants, N }\end{array}$ & $\begin{array}{l}\text { Non- } \\
\text { participants, } \mathrm{N}\end{array}$ \\
\hline
\end{tabular}

Job type (based on one-digit DISCO08)

\begin{tabular}{|c|c|c|c|c|c|c|}
\hline Managers & 48.9 & 779 & 815 & 54.9 & 376 & 309 \\
\hline Professionals & 60.0 & 5378 & 3585 & 63.8 & 2594 & 1473 \\
\hline $\begin{array}{l}\text { Technicians and associate } \\
\text { professionals }\end{array}$ & 55.0 & 2282 & 1867 & 57.6 & 950 & 698 \\
\hline Clerical support workers & 53.1 & 1627 & 3295 & 55.8 & 546 & 432 \\
\hline Service and sales workers & 45.6 & 2767 & 1439 & 51.6 & 1552 & 1457 \\
\hline $\begin{array}{l}\text { Craft and related trades } \\
\text { workers }\end{array}$ & 45.2 & 1258 & 1525 & 44.8 & 879 & 1082 \\
\hline $\begin{array}{l}\text { Plant and machine } \\
\text { operators, and assemblers }\end{array}$ & 47.7 & 824 & 905 & 49.0 & 555 & 578 \\
\hline Elementary occupations & 41.6 & 2431 & 3407 & 47.4 & 1002 & 1110 \\
\hline
\end{tabular}

The other factors of interest were included in the logistic regression models as categorical variables categorised as in the descriptive analyses. The associations with age by sex and income were displayed graphically and the associations with the other variables were presented in tables.

\section{Sensitivity analyses}

We excluded the 1400 individuals with no information on education and evaluated whether this changed the results.

\section{Software}

The statistical analyses were performed using the GLIMMIX procedure in SAS V.9.4 (SAS Institute) and the plots were performed using R V.3.1.2 (The R Foundation).

\section{Patient and public involvement}

There is no patient and public involvement in this study.

\section{RESULTS}

A total of $48 \%$ of the participants completed the web questionnaire and $52 \%$ the paper questionnaire, and $52 \%$ responded before the telephone reminder.

\section{Characteristics of the study population}

Table 1 shows the characteristics of participants and non-participants in the random sample of 34805 eligible employees as well as in the stratified workplace sample of 15675 eligible employees. A total of 17591 employees $(50.5 \%)$ participated in the random sample of the survey. The two most prevalent job types in the random sample were professionals having the highest participation of
$60 \%$ and elementary occupations having the lowest participation of $41.6 \%$. The usual pattern for participation was seen for the other socio-demographic variables: women were more likely to participate than men, participation increased with age, personal income, higher education, cohabitation and Danish origin. Similar results were found for the workplace sample.

\section{Results from regression analyses}

Results from the logistic regression analysis of participation status in relation to job type and other socio-demographic factors can be seen in table 2 and figures 2 and 3 . Table 2 shows that compared with professionals, the low participation among armed forces occupations (OR 0.46), craft and related trades workers (OR 0.52) and skilled agricultural, forestry and fishery workers (OR 0.59) was clearly increased by adjustment for sex and age (model 2: OR $0.85,0.72$ and 0.72 , respectively). Further adjustment for the remaining socio-demographic variables generally attenuated the association between participation and job type, but the association with job type remained statistically significant (model 4: $\mathrm{p}<0.0001$ ). The adjustment for job type slightly attenuated the associations with education and cohabitation (model 4 compared with model 3), whereas adjustment for the other socio-demographic factors was more important regarding the association with country of origin (model 3 compared with model 2). However, all socio-demographic factors remained statistically significant in all investigated model. Similar results were found for the workplace sample, see online supplementary appendix table 1 .

Figure 2 shows OR for participation by sex and age in 1-year categories. The crude ORs (model 1) were 
Table 2 Logistic regression analyses on job type, other socioeconomic factors and participation status presented as crude and mutually adjusted OR $(95 \% \mathrm{Cl})$ in the random sample of Work, Environment and Health $2012(\mathrm{n}=34805)$

\begin{tabular}{|c|c|c|c|c|}
\hline & \multirow[b]{2}{*}{ Model 1* } & \multicolumn{2}{|c|}{ Participation versus non-participation } & \multirow[b]{2}{*}{ Model 4§ } \\
\hline & & Model 2† & Model 3‡ & \\
\hline Job type, $p$ value & $<0.0001$ & $<0.0001$ & & $<0.0001$ \\
\hline Managers & 0.65 (0.60 to 0.71$)$ & 0.66 (0.60 to 0.72$)$ & & 0.76 (0.69 to 0.84$)$ \\
\hline Professionals & 1 & 1 & & 1 \\
\hline Technicians and associate professionals & $0.80(0.75$ to 0.85$)$ & $0.79(0.74$ to 0.84$)$ & & $0.92(0.86$ to 0.99$)$ \\
\hline Clerical support workers & 0.74 (0.69 to 0.79$)$ & 0.74 (0.69 to 0.84$)$ & & 0.94 (0.86 to 1.02$)$ \\
\hline Service and sales workers & 0.58 (0.55 to 0.61$)$ & 0.63 (0.59 to 0.67$)$ & & 0.85 (0.79 to 0.91$)$ \\
\hline $\begin{array}{l}\text { Skilled agricultural, forestry and fishery } \\
\text { workers }\end{array}$ & 0.59 (0.45 to 0.76$)$ & 0.72 (0.55 to 0.95$)$ & & $0.93(0.71$ to 1.22$)$ \\
\hline Craft and related trades workers & 0.52 (0.49 to 0.56$)$ & $0.72(0.67$ to 0.77$)$ & & 0.88 (0.81 to 0.96$)$ \\
\hline $\begin{array}{l}\text { Plant and machine operators, and } \\
\text { assemblers }\end{array}$ & 0.59 (0.54 to 0.64$)$ & 0.64 (0.59 to 0.70$)$ & & 0.91 (0.82 to 1.00$)$ \\
\hline Elementary occupations & 0.48 (0.46 to 0.51$)$ & 0.54 (0.50 to 0.57$)$ & & 0.79 (0.74 to 0.85$)$ \\
\hline Armed forces occupations & 0.46 (0.37 to 0.57$)$ & 0.85 (0.68 to 1.06$)$ & & 0.98 (0.78 to 1.22$)$ \\
\hline No DISCO code & 0.07 (0.04 to 0.14$)$ & $0.14(0.07$ to 0.26$)$ & & 0.44 (0.22 to 0.86$)$ \\
\hline Country of origin, $p$ value & $<0.0001$ & $<0.0001$ & $<0.0001$ & $<0.0001$ \\
\hline Denmark & 1 & 1 & 1 & 1 \\
\hline Western country, not Denmark & 0.52 (0.47 to 0.57$)$ & 0.58 (0.52 to 0.64$)$ & $0.82(0.71$ to 0.95$)$ & 0.83 (0.71 to 0.96$)$ \\
\hline Non-Western country & 0.47 (0.43 to 0.51$)$ & 0.55 (0.51 to 0.60$)$ & 0.70 (0.62 to 0.78$)$ & 0.72 (0.64 to 0.81$)$ \\
\hline Cohabitation, $p$ value & $<0.0001$ & $<0.0001$ & $<0.0001$ & $<0.0001$ \\
\hline Married or unmarried couple & 1 & 1 & 1 & 1 \\
\hline Living alone & 0.71 (0.67 to 0.75$)$ & 0.75 (0.71 to 0.80$)$ & 0.76 (0.72 to 0.81$)$ & $0.76(0.72$ to 0.81$)$ \\
\hline More families living together & 0.53 (0.50 to 0.57$)$ & 0.64 (0.60 to 0.69$)$ & 0.73 (0.68 to 0.78$)$ & 0.74 (0.68 to 0.79$)$ \\
\hline Education, $p$ value & $<0.0001$ & $<0.0001$ & $<0.0001$ & $<0.0001$ \\
\hline Compulsory school system & $0.73(0.69$ to 0.77$)$ & 0.71 (0.67 to 0.76$)$ & $0.74(0.70$ to 0.79$)$ & $0.76(0.71$ to 0.81$)$ \\
\hline $\begin{array}{l}\text { Upper secondary education, vocational } \\
\text { education, etc. }\end{array}$ & 1 & 1 & 1 & 1 \\
\hline Academic level & 1.54 (1.47 to 1.62$)$ & 1.41 (1.33 to 1.48$)$ & 1.45 (1.37 to 1.53$)$ & 1.34 (1.25 to 1.43$)$ \\
\hline Missing education, Danish origin & 0.57 (0.40 to 0.83$)$ & 0.49 (0.34 to 0.92$)$ & $0.51(0.35$ to 0.75$)$ & 0.53 (0.36 to 0.78$)$ \\
\hline $\begin{array}{l}\text { Missing education, Western origin, not } \\
\text { Danish }\end{array}$ & 0.26 (0.21 to 0.32$)$ & $0.35(0.28$ to 0.44$)$ & 0.49 (0.38 to 0.64$)$ & 0.52 (0.40 to 0.68$)$ \\
\hline Missing education, non-Western origin & 0.27 (0.20 to 0.36$)$ & $0.38(0.28$ to 0.51$)$ & $0.64(0.46$ to 0.88$)$ & 0.68 (0.50 to 0.95$)$ \\
\hline Region in Denmark, $p$ value & $<0.0001$ & $<0.0001$ & $<0.0001$ & $<0.0001$ \\
\hline Copenhagen (capital) & 0.93 (0.86 to 1.00$)$ & 0.95 (0.88 to 1.03$)$ & 0.95 (0.87 to 1.02$)$ & 0.94 (0.87to 1.02) \\
\hline Zealand & 1.03 (0.94 to 1.12$)$ & 0.96 (0.88 to 1.05$)$ & $0.96(0.88$ to 1.05$)$ & 0.96 (0.88 to 1.05$)$ \\
\hline Northern Jutland & 1 & 1 & 1 & 1 \\
\hline Middle Jutland & 1.10 (1.02 to 1.19$)$ & 1.11 (1.02 to 1.20$)$ & 1.09 (1.00 to 1.18$)$ & 1.09 (1.00 to 1.18$)$ \\
\hline Southern Denmark & $1.12(1.03$ to 1.21$)$ & 1.11 (1.02 to 1.20$)$ & $1.10(1.02$ to 1.20$)$ & $1.11(1.02$ to 1.20$)$ \\
\hline
\end{tabular}

${ }^{*}$ Model 1: OR for each factor separately.

†Model 2: OR for each factor separately adjusted for age*sex.

¥Model 3: OR mutually adjusted and further adjusted for age*sex and income (as a spline function).

§Model 4: model 3+job type.

higher for women compared with those for men for all age groups, except for employees aged 64years, where men and women had similar ORs. There was a steadily increasing participation with age among both men and women, except that men aged 20 years or younger had a higher OR for participation compared with men aged 20-26years. When adjusted for all socio-demographic factors except job type (model 3), the lower participation 

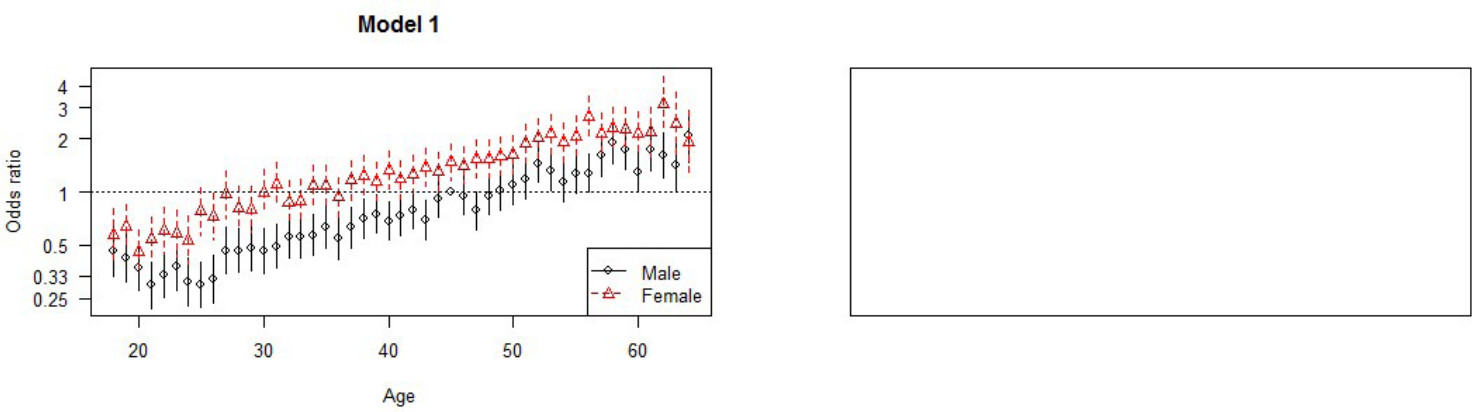

Model 3
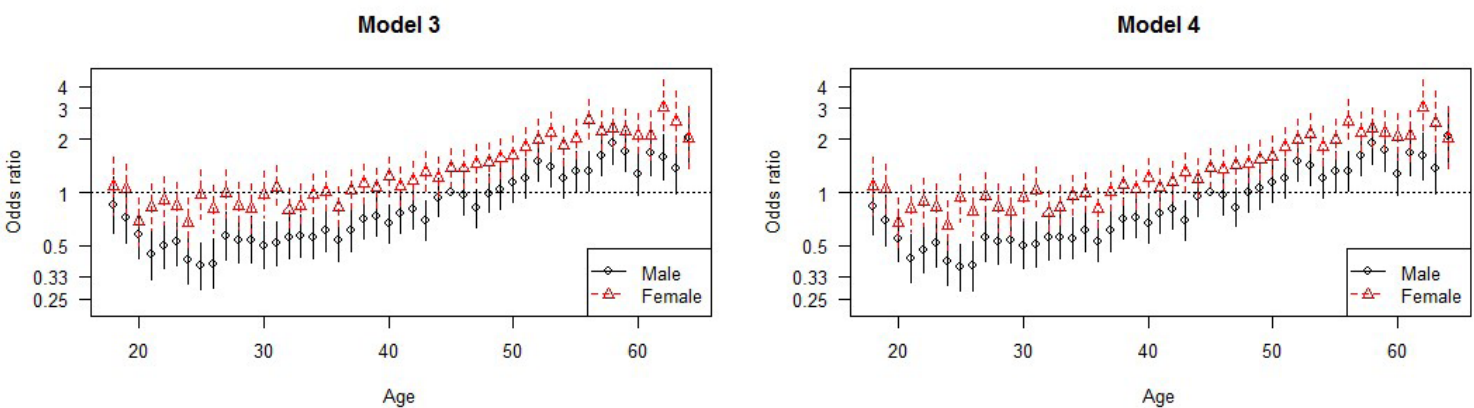

Figure $2 \mathrm{OR}(95 \% \mathrm{Cl})$ for participation by sex and age in 1-year categories for employees in the random sample of Work, Environment and Health 2012. Model 1: Crude OR by age and sex. Model 3: OR adjusted for country of origin, cohabitation, education, region, age*sex and annual income (as a spline function). Model 4: model 3+job type. Reference value: men aged 45 years.
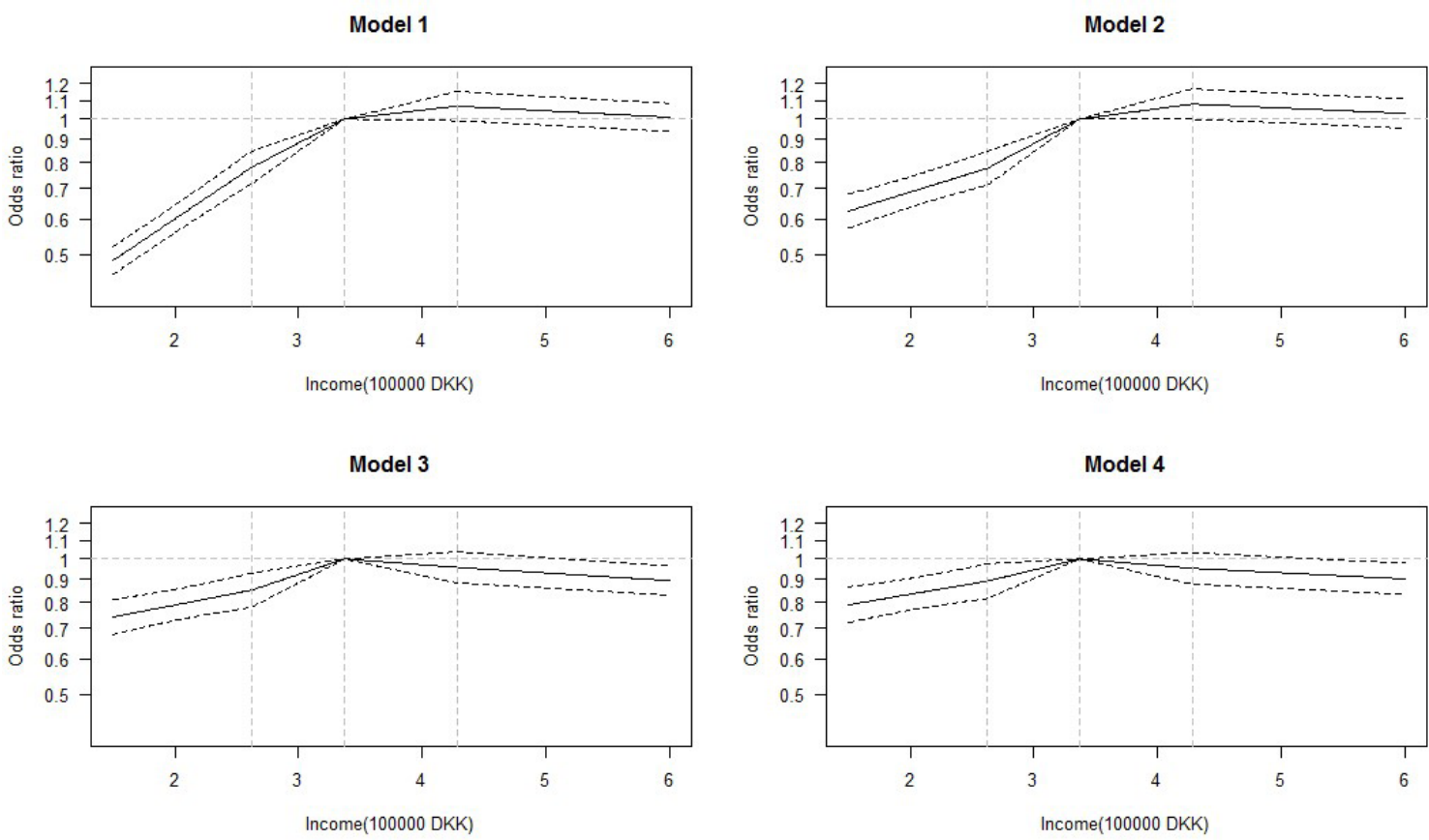

Figure $3 \mathrm{OR}(95 \% \mathrm{Cl})$ for participation by annual, personal income (as spline function) among 34805 employees in the random sample of Work, Environment and Health 2012. Reference value: the median income, 353000 Danish Krones ( US $\$ 50000)$. Model 1: crude OR by income. Model 2: model 1 adjusted for age*sex. Model 3: model 2 further adjusted for country of origin, cohabitation, education, region and age*sex. Model 4: model 3 further adjusted for job type.

among 18-25-year-old individuals compared with same-sex older individuals disappeared, but the difference between the two sexes remained. Additional adjustment for job type (model 4) made almost no difference.
For individuals above 26years of age, the ORs in the crude and adjusted analyses were similar. Similar results were found for the workplace sample, online supplementary appendix figure 1. 
ORs for participation by personal income with the median income as reference can be seen in figure 3. In the crude analysis a gradual increase from OR 0.5 for employees with the lowest income to OR slightly above 1 for employees with the highest income was evident. Adjustment for age by sex slightly attenuated the association below the median income (model 3). Further adjustment for education, cohabitation, country of origin and region clearly attenuated the associations across the whole range (model 3), whereas additional adjustment for job type made no difference (model 4). Similar results were found for the workplace sample, online supplementary appendix figure 2 .

\section{Results from sensitivity analyses}

Excluding the 1400 individuals with no information on education did not change the results substantially.

\section{DISCUSSION}

\section{Key results}

The results of this study showed that participation in WEHD 2012 varied between job types. This variation was partly explained by differences in sex and age for armed forces occupations, craft and related trade workers, and skilled agricultural, forestry and fishery workers, and by personal income, education, cohabitation, country of origin, and geographical region for all job types. All socio-demographic factors remained statistically significant when mutually adjusted.

\section{Strengths and limitations}

The major strengths of this study are the large sample size, the national coverage and the access to almost complete registry data available for both participants and non-participants. Potential limitations are the relatively crude job groups, and missing information on education for 1400 individuals. The sensitivity analysis addressed the potential limitation on missing data. Unfortunately, we did not have sufficient statistical power to conduct analyses with more detailed job groups.

Furthermore, some job groups were small. For example, the number of employees with no DISCO code is 84; consequently, the result for this group could potentially be affected by sparse data bias and should therefore be interpreted with caution. ${ }^{21}$

In a cross-sectional study like this, all the variables are measured at the same point in time; therefore, cross-sectional studies are not well suited for drawing any conclusions about causality. However, in this study our scope was to characterise participants and assess associations between individual, characteristics based on registry data, and therefore, temporality is not a major concern.

\section{Previous studies}

Our results confirm previous studies with regard to the importance of socio-demographic factors like sex and age, education and socioeconomic indicators for survey participation. ${ }^{6710-17}$ Furthermore we were able to show that job type can be added to this list as an independent predictor of survey participation, at least in a study on work environment and health.

Studies have shown that follow-up procedures, ${ }^{22}$ a relevant study aim (potentially affecting the individual in question), and monetary incentives can be used to increase participation rates. ${ }^{23}$ However, the effect of monetary incentives was related to education and income. ${ }^{24}$ It has also been shown that applying different data collection methods on different population subgroups can increase participation rates and produce more representative samples. For example face-to-face recruitment and data collection, ${ }^{25}$ telephone interviews or printed letters can be used as an alternative to mail/web-based surveys or vice versa. ${ }^{26-31}$ In such case, the researchers need to weigh the benefit of higher participation against the possibility that participation as well as actual answers to a given question may differ according to the method used. In contrast, long and exhaustive questionnaires, difficult accessibility to the questionnaire, or both, are typically associated with lower participation. ${ }^{32}$

Therefore, questionnaires should first be designed to be easily accessible and then different incentives and data collection methods (including stratified sampling) may be considered. However, it is important to note that low participation not necessarily means a high level of bias and that, vice versa, a high participation not necessarily means a low level of bias. Some efforts to increase participation may in fact increase bias if the consequence of this effort is selective participation, or unwillingness to participate in future studies.

\section{Concluding remarks}

In this population of Danish employees, we found a relatively small but independent effect of job type on participation. We also found socio-demographically imbalanced participation as reported in previous survey studies. The low participation in the age groups below 25 years of age could be explained by the socio-demographic factors, personal income, education, cohabitation, country of origin and geographical region of residence. Further adjustment for job type did not change the estimated association with sex and age.

Future studies using questionnaires may consider using different data collection methods and incentives for different (sub-)populations defined by job type and other factors, for example face-to-face interviews in populations with low education or elementary occupations, and monetary incentives in the younger age groups.

The authors believe that the results of this study on participation in the WEHD2012 can be generalised to the general Danish work force aged 18-64years because they are represented by the random sample of this study and because registry data are used. 


\section{Ethics}

Because the study did not include biological samples, no further approval was required. According to the Helsinki Declaration participants were informed that participation was voluntary and that they could withdraw themselves (and their data) from the study at any time.

Contributors BLT and JVH established a strategy for the statistical analyses. NFJ, JVH, BSC and BLT conducted the statistical analyses. NFJ interpreted the results in close cooperation with the rest of the authors (JVH, BSC, VS, BLT, RR). NFJ and VS drafted the manuscript. All the authors read and approved the final version of the manuscript.

Funding This research received no specific grant from any funding agency in the public, commercial or not-for-profit sectors.

Competing interests None declared.

Patient consent for publication Not required.

Ethics approval The Work Environment and Health Survey was registered and approved by the Danish Data Protection Agency (journal number 2015-57-0074).

Provenance and peer review Not commissioned; externally peer reviewed.

Data sharing statement All relevant source data are shown in the manuscript and supplementary files. If access to raw data is required, please contact Nina Føns Johnsen at nfj@nfa.dk. Data may be shared if all ethical and legal requirements are met.

Open access This is an open access article distributed in accordance with the Creative Commons Attribution Non Commercial (CC BY-NC 4.0) license, which permits others to distribute, remix, adapt, build upon this work non-commercially, and license their derivative works on different terms, provided the original work is properly cited, appropriate credit is given, any changes made indicated, and the use is non-commercial. See: http://creativecommons.org/licenses/by-nc/4.0/.

\section{REFERENCES}

1. Hartge P. Raising response rates: getting to yes. Epidemiology 1999;10:105-7.

2. Nohr EA, Frydenberg M, Henriksen TB, et al. Does low participation in cohort studies induce bias? Epidemiology 2006;17:413-8.

3. Christensen Al, Ekholm O, Kristensen PL, et al. The effect of multiple reminders on response patterns in a Danish health survey. Eur $J$ Public Health 2015;25:156-61.

4. Austin MA, Criqui MH, Barrett-Connor E, et al. The effect of response bias on the odds ratio. Am J Epidemiol 1981;114:137-43.

5. Stang A. Nonresponse research--an underdeveloped field in epidemiology. Eur J Epidemiol 2003;18:929-32.

6. Lundberg I, Damström Thakker K, Hällström T, et al. Determinants of non-participation, and the effects of non-participation on potential cause-effect relationships, in the PART study on mental disorders. Soc Psychiatry Psychiatr Epidemiol 2005;40:475-83.

7. Johannessen A, Verlato G, Benediktsdottir B, et al. Longterm followup in European respiratory health studies - patterns and implications. BMC Pulm Med 2014;14:63.

8. Pearl J, Bareinboim E. External Validity: From Do-Calculus to Transportability Across Populations. Statistical Science 2014;29:579-95.

9. Pearl J. Generalizing of Experimental Findings. J Causal Infer 2015;3:259-66.
10. Korkeila K, Suominen S, Ahvenainen J, et al. Non-response and related factors in a nation-wide health survey. Eur $\mathrm{J}$ Epidemiol 2001;17:991-9.

11. Sogaard AJ, Selmer R, Bjertness E, et al. The Oslo Health Study: the impact of self-selection in a large, population-based survey. Int $J$ Equity Health 2004;3(1:3.

12. Stang A, Moebus S, Dragano N, et al. Baseline recruitment and analyses of nonresponse of the Heinz Nixdorf Recall Study: identifiability of phone numbers as the major determinant of response. Eur J Epidemiol 2005;20:489-96.

13. Martikainen $\mathrm{P}$, Laaksonen $\mathrm{M}$, Piha $\mathrm{K}$, et al. Does survey non-response bias the association between occupational social class and health? Scand J Public Health 2007;35:212-5.

14. Shahar E, Folsom AR, Jackson R. The effect of nonresponse on prevalence estimates for a referent population: Insights from a population-based cohort study. Ann Epidemiol 1996;6:498-506.

15. Fejer R, Hartvigsen J, Kyvik KO, et al. The Funen Neck and Chest Pain study: analysing non-response bias by using national vital statistic data. Eur J Epidemiol 2006;21:171-80.

16. Huang N, Shih SF, Chang HY, et al. Record linkage research and informed consent: who consents? BMC Health Serv Res 2007;7:18.

17. Jacobsen TN, Nohr EA, Frydenberg M. Selection by socioeconomic factors into the Danish National Birth Cohort. Eur J Epidemiol 2010;25:349-55.

18. Pedersen CB. The Danish Civil Registration System. Scand J Public Health 2011;39:22-5.

19. Baadsgaard M, Quitzau J. Danish registers on personal income and transfer payments. Scand J Public Health 2011;39:103-5.

20. International Labour Organization,. International Standard Classification of Occupations [online]. 2018. Available at http://www. ilo.org/public/english/bureau/stat/isco/isco08/ (accessed Apr 2018).

21. Greenland S, Mansournia MA, Altman DG. Sparse data bias: a problem hiding in plain sight. BMJ 2016;352:i1981.

22. Collins RL, Ellickson PL, Hays RD, et al. Effects of incentive size and timing on response rates to a follow-up wave of a longitudinal mailed survey. Eval Rev 2000;24:347-63.

23. James JM, Bolstein R. The Effect of Monetary Incentives and FollowUp Mailings on the Response Rate and Response Quality in Mail Surveys. Public Opin Q 1990;54:346-61.

24. Singer E, Groves RM, Dillman DA, Eltinger JL, Little RJA, et al. eds. The use of incentives to reduce nonresponse in household surveys. New York, NY: Wiley-Interscience, 2002:163-77.

25. Bongers IM, Van Oers JA. Mode effects on self-reported alcohol use and problem drinking: mail questionnaires and personal interviewing compared. J Stud Alcohol 1998;59:280-5.

26. O'Toole BI, Battistutta $\mathrm{D}$, Long $\mathrm{A}$, et al. A comparison of costs and data quality of three health survey methods: mail, telephone and personal home interview. Am J Epidemiol 1986;124:317-28.

27. Brambilla DJ, McKinlay SM. A comparison of responses to mailed questionnaires and telephone interviews in a mixed mode health survey. Am J Epidemiol 1987;126:962-71.

28. Fowler FJ, Gallagher PM, Stringfellow VL, et al. Using telephone interviews to reduce nonresponse bias to mail surveys of health plan members. Med Care 2002;40:190-200.

29. Zaslavsky AM, Zaborski LB, Cleary PD. Factors affecting response rates to the Consumer Assessment of Health Plans Study survey. Med Care 2002;40:485-99.

30. McMahon SR, Iwamoto M, Massoudi MS, et alPediatrics 2003;111:e299-e303.

31. Beebe TJ, Davern ME, McAlpine DD, et al. Increasing response rates in a survey of Medicaid enrollees: the effect of a prepaid monetary incentive and mixed modes (mail and telephone). Med Care 2005;43:411-4.

32. Mott DA, Pedersen CA, Doucette WR, et al. A national survey of US pharmacists in 2000: assessing non-response bias of a survey methodology. AAPS Pharm Sci 2000;3:E33. 